\title{
Perception and Experience Regarding Menopause among Menopaused Women Attending Teaching Hospitals in Erbil City
}

\author{
Gazang Najmaddin Mustafa ${ }^{1}$ \& Jwan Muhamad Sabir ${ }^{2}$ \\ ${ }^{1}$ Nazdar Bamarny Family center, Erbil, Iraq \\ ${ }^{2}$ Community Medicine Department, College of Medicine, Hawler Medical University, Erbil, Iraq \\ Correspondence: Dr Jwan Muhamad Sabir, Lecturer in Community Medicine Department, College of Medicine, \\ Hawler Medical University, Erbil, Iraq. Tel: 964-750-496-6174. E-mail: jwan1964@yahoo.com
}

\author{
Received: February 6, 2012 Accepted: February 20, 2012 Online Published: May 1, 2012 \\ doi:10.5539/gjhs.v4n3p170 URL: http://dx.doi.org/10.5539/gjhs.v4n3p170
}

\begin{abstract}
Background and Objectives: The timing of menopause, perception as well as menopausal symptoms varies between populations and within populations. The main objective of the present study was to assess women's perception and experience regarding menopause, to find out symptoms and mean age of menopause and to study socio-demographic characteristics of menopaused women and to find out its relationship with their age at menopause and their knowledge about menopause. Methods: Over a period of eight months a descriptive cross sectional study were carried out at the outpatient departments of four teaching hospitals in Erbil city. A total of 500 menopaused women their age ranged from 40-60 years were interviewed using a close ended self administered questionnaire. Results: Mean age of menopause was 47.44 years with median age was 48 years, $4.4 \%$ had premature menopause and $23.6 \%$ had early menopause. The only factors that significantly associated with age at menopause were education and pattern of menstrual cessation and $93.4 \%$ of menopaused women were heard about menopause, $56.6 \%$ had prior knowledge of menopausal symptoms, cessation of menstruation was positive in $47.0 \%$ and $85.8 \%$ of women perceive menopause as natural condition and the most common menopausal symptoms were tiredness occurring in $83.2 \%$. Conclusion: Most of menopaused women perceive menopause as natural condition and not aware about hormone replacement therapy and the mean age of menopause is comparable to that mean reported in other part of Iraq. Among menopaused women tiredness was the most common complaint was followed by hot flushes and night sweats.
\end{abstract}

Keywords: menopause, age at menopause, perception, menopausal symptoms

\section{Introduction}

The term menopause means the end of the monthly menstrual cycle which is the central external marker of human female fertility and a natural menopause is deemed to have occurred after 6 months of secondary amenorrhea in a women aged 45 years or over (Edmonds et al, 2006). All women who live long enough will make transition to menopause (Wong et al, 2001). The menopause is based on the natural or surgical cessation of estrogen and progesterone production by the ovaries, which are a part of the body's endocrine system of hormone production; in this case the hormones which make reproduction possible and can influence sexual behavior. Two hundred years ago only $30 \%$ of women lived through a menopause; now more than $90 \%$ will. Thus, the menopause transition and post menopause is very much a condition of the $20^{\text {th }}$ and $21^{\text {st }}$ centuries (Panay, 2007). As the world population increases and a large proportion of this population is made up of individuals older than 50 , medical care specifically directed at post menopause women becomes an important aspect of modern medicine (Lobo, 2007). Age at which natural menopause occurs is between the ages of 45 and 55 for women worldwide. It is generally accepted that the average age at menopause is about 51 years in industrialized countries, but data are inconsistent for the developing world because of methodological problem (WHO, 1996). The most important factor determining a woman's age at the menopause is the number of ovarian follicles (Block, 1952) and socio-demographic and behavioral characteristics found to have effect on determining the age at menopause (Ayatollahi et al, 2005).

Numerous factors including menopausal status, social background, and education, physical and emotional health may influence women's knowledge and believes about menopause (Theisen et al, 1995; Avis and Mckinley, 1991). Attitudes, perceptions and expectations are part of the psychosocial phenomenon surrounding menopause 
(Avis, 1996) also there is an assumption in menopause research that attitudes to menopause are influenced by a range of cultural and social variables, which may in turn affect menopausal experience and symptom reporting (Ayers et al, 2010). A perception of the menopause as a positive event varies in different countries between 60\%-90\% (Leon et al, 2007; Kowalcek et al, 2005; Sallam et al, 2006) and menopausal symptoms are found to be less common in societies where menopause is viewed as positive rather than negative event.

The consequence of menopause are: (1) Immediate which involve: hot flushes, sweats, insomnia, anxiety, irritability, memory loss, tiredness, poor concentration, reduction in libido, (2) Intermediate: dyspareunia, dysuria, urgency, frequency, general aches, (3) Long term: osteoporosis, cardiovascular disease and dementia (Panay, 2007). Menopausal symptoms can really have an important impact in the daily, social and sexual life of postmenopausal women (Hassa et al, (2005).

Studies on women's perception and experience regarding menopause and age at menopause are available from several Middle Eastern countries Age at menopause has been studied in Baghdad (Dhia Al-Deen and Sadik, 2009).

Rational: no similar study has been done in Kurdistan of Iraq especially in Erbil city regarding menopause.

\subsection{Aim}

This study was carried out to assess perception and experience regarding menopause among menopaused women and to evaluate their practicing at age of menopause in Erbil city.

\section{Subject and Methods}

A descriptive cross- sectional study was carried out over a period of eight months from $1^{\text {st }}$ August 2010 to $1^{\text {st }}$ April 2011and this study was conducted at the outpatient department of the Maternity, Rizgary, Hawler and Raparin Teaching Hospitals. A convenience sample of 500 menopaused women of age 40-60 years was collected by direct interview and women who had a natural menopause included in this study. Women who underwent a hysterectomy or oophorectomy prior to their natural menopause and women who are complaining from symptoms due to medical diseases and past history of psychiatric disorder excluded from this study. A verbal consent was taken from each recruited respondent and informed that participation in the study was voluntary and permission was obtained from Directorate of Health and the four teaching hospitals in Erbil city to carry out the study.

A close ended self administered questionnaire was used to collect the information regarding socio demographic characteristics which include: name, age, residence, marital status, income, occupation, years of formal education and crowding index, menstrual and reproductive history with pattern of menstrual cessation, age of menopause (the age was directly recorded for those women who could remember the date correctly; women who could not remember were assisted by reference to dates of important events). In this study the age of menopause was grouped in to three classes $<45$ years, $45-49$ years and $>49$ years( this classification depend on considering that early menopause less than 45 years (Panay, 2007) and premature menopause less than 40 years (WHO, 1996)then we arranged other two age groups to avoid recruited of all menopausal women in one age group to get good analysis data. Questions related to perception, practices, physical and psychological symptoms experienced by menopaused women were recorded.

\subsection{Statistical Analysis}

Questionnaires were coded after cleaning was done. Data were entered and analyzed using statistical packages for social sciences (SPSS, version 18). Two approaches were used; descriptive and analytic. The descriptive approach included calculation of the frequencies, percentages, mean SD.s and the second approach; $t$ test was used to compare between means of two different samples, analysis of variance (ANOVA) that indicated by F sign was used to compare between more than two means. Chi-square test and Fisher's exact test were used to test the association between categorical variables.

\section{Results}

In the study sample, age of menopause ranged from 37- 56 years with mean \pm S D of $47.44 \pm 4.35$, median age of menopause was 48.00 years, $23.6 \%$ of women had menopause at the age of $<45$ years, $40.4 \%$ between age $45-49$ years and $36.0 \%$ at the age of $>49$ years.

Age of women's reported onset of menopause; $0.2 \%$ had their menopause at the age of 37 years, $0.4 \%$ had the menopause at the age of 56 years, $4.4 \%$ had premature menopause and $23.6 \%$ had early menopause. 
Table 1. Socio demographic characteristic of the study sample $(n=500)$

\begin{tabular}{clll}
\hline Variable & No. & Variable & No. \\
\hline Age of women (year) & & Occupation & \\
$40-44$ & 11 & Housewife & 420 \\
$45-49$ & 86 & Manual partly skilled or unskilled & 35 \\
$50-54$ & 159 & Non-manual skilled or semi skilled & 41 \\
$\geq 55$ & 244 & Professional occupation & 4 \\
\hline Residence & & Years of formal education & \\
Rural & 42 & $0^{*}$ & 355 \\
Urban & 458 & $1-6$ & 71 \\
\hline Marital status & & $7-9$ & 15 \\
Single & 4 & $10-12$ & 11 \\
Married & 355 & $\geq 13$ & 48 \\
Widowed & 139 & Crowding index & 149 \\
Divorced & 2 & $<1.5$ & 234 \\
\hline Income & & $1.5-2.9$ & 117 \\
Poor & 60 & $\geq 3$ & \\
Low & 157 & & \\
Middle & 272 & & \\
High & 11 & &
\end{tabular}

*Illiterate and unschooled

As shown in Table 1, among 500 menopaused women who had natural menopause 458 from urban areas, 42 from rural areas.The highest age group of menopaused women were $\geq 55$ years old with mean age was 53.6 years. Concerning the marital status most of menopaused women were married and the majority of menopaused women were housewives.

Table 2. Distribution of women according to their perception $(n=500)$

\begin{tabular}{lc}
\hline \multicolumn{1}{c}{ Perception } & No. \\
\hline Women had heard about menopause? & 467 \\
Previous knowledge of menopausal symptoms & 283 \\
Is it life altering? & 356 \\
Is it positive thing? & 235 \\
Is it natural or medical condition? & \\
$\quad$ Natural & 429 \\
$\quad$ Medical & 71 \\
Women must consult a physician? & 377 \\
Awareness about Hormone Replacement Therapy? & 68 \\
What foods are suitable for menopause women? & \\
Fruits and vegetables & 191 \\
Meats & 6 \\
Dairy products & 54 \\
Non specific foods & 249 \\
\hline
\end{tabular}

As shown in Table 2, most of menopaused women heard about menopause and perceived menopause as a natural condition and the highest percentage of women said that their lives altered after cessation of menstruation. 
Table 3. Distribution of women according to practices

\begin{tabular}{lc}
\hline Practices & No. \\
\hline Did she consult a physician? (after menopause) & 245 \\
Did she smoke? & \\
$\quad$ Smoker & 76 \\
Non smoker & 412 \\
Ex smoker & 12 \\
Did she discuss menopausal symptoms with doctors? & 233 \\
Did menopausal state affect on sexual desire? & 173 \\
Did she tell her husband about her menopause? & 424 \\
\hline
\end{tabular}

Table 4. Association of menopause age with smoking

\begin{tabular}{|c|c|c|c|c|c|c|}
\hline \multirow{2}{*}{ Smoking } & \multirow{2}{*}{$\begin{array}{l}\text { Total } \\
\text { No }\end{array}$} & \multirow{2}{*}{$\begin{array}{l}\text { Mean } \pm \text { SD of } \\
\text { menopause age }\end{array}$} & \multicolumn{3}{|c|}{ menopause age group } & \\
\hline & & & $<45 \mathrm{No}(\%)$ & 45-49 No(\%) & $>49$ No(\%) & \\
\hline Non smoker & 412 & $47.44 \pm 4.35$ & $99(24.0)$ & $157(38.1)$ & $156(37.9)$ & $\begin{array}{l}\chi^{2}=5.49, \\
P=0.064\end{array}$ \\
\hline Smoker & 76 & $47.30 \pm 4.33$ & $17(22.4)$ & $38(50.0)$ & 21(27.6) & $\begin{array}{l}\chi^{2}=3.85, \\
P=0.146\end{array}$ \\
\hline Ex-smoker & 12 & $48.08 \pm 4.96$ & $2(16.7)$ & $7(58.3)$ & $3(25.0)$ & $\mathrm{NA}^{*}$ \\
\hline \multirow[t]{2}{*}{ Total } & 500 & $47.44 \pm 4.35$ & $118(23.6)$ & $202(40.4)$ & $180(36.0)$ & \\
\hline & \multicolumn{6}{|c|}{$\mathrm{F}=0.168, \mathrm{P}=0.845$} \\
\hline
\end{tabular}

* Chi- square test not applicable

Table 3 shows practices related to menopause; half of women not consult a physician after menopause and most of them were not smokers with no significant association between smoking habit and age at menopause with $\mathrm{P}$ value $>0.05$ as showmen in table 4 .

Table 5. Physical and psychological symptoms experienced by menopaused women

\begin{tabular}{lc}
\hline Menopausal symptoms & No. \\
\hline Tiredness & 416 \\
Hot flushes & 357 \\
Night sweats & 345 \\
Insomnia & 232 \\
Vaginal dryness & 259 \\
Dypareunnia & 80 \\
Urinary frequency & 154 \\
Dysuria & 118 \\
Urgency & 111 \\
Mood swings & 207 \\
Anxiety & 214 \\
Loss of short term memory & 293 \\
Poor concentration & 269 \\
Loss of self-confidence & 20 \\
Depressed mood & 47 \\
\hline
\end{tabular}

Table 5 shows that, tiredness was the most common complaint among physical symptoms and this complaint was followed by hot flushes and night sweats. About psychological symptoms, most common complaint was loss of short term memory followed by poor concentration. 
Table 6. Association of menopause age with education

\begin{tabular}{|c|c|c|c|c|c|c|}
\hline \multirow{2}{*}{$\begin{array}{l}\text { Years of } \\
\text { formal } \\
\text { education }\end{array}$} & \multirow[b]{2}{*}{ Total No } & \multirow{2}{*}{$\begin{array}{l}\text { Mean } \pm \text { SD of } \\
\text { menopause age }\end{array}$} & \multicolumn{3}{|c|}{ menopause age group } & \\
\hline & & & $<45$ No(\%) & $45-49$ No(\%) & $>49$ No(\%) & \\
\hline 0 & 355 & $47.46 \pm 4.42$ & $82(23.1)$ & $150(42.3)$ & $123(34.6)$ & $\begin{array}{l}\chi^{2}=1.79 \\
P=0.407\end{array}$ \\
\hline $1-6$ & 71 & $47.28 \pm 4.37$ & $22(31.0)$ & $22(31.0)$ & $27(38.0)$ & $\begin{array}{l}\chi^{2}=3.82 \\
P=0.147\end{array}$ \\
\hline 7-9 & 15 & $46.26 \pm 5.27$ & $4(26.7)$ & $5(33.3)$ & $6(40.0)$ & $\begin{array}{l}\chi^{2}=0.32, \\
P=0.851\end{array}$ \\
\hline $10-12$ & 11 & $45.00 \pm 3.68$ & $7(63.6)$ & $3(27.3)$ & $1(9.1)$ & $\mathrm{NA}^{*}$ \\
\hline$\geq 13$ & 48 & $48.43 \pm 3.39$ & $3(6.3)$ & $22(45.8)$ & $23(47.9)$ & $\chi^{2}=9.26$ \\
\hline \multirow[t]{2}{*}{ Total } & 500 & $47.44 \pm 4.35$ & $118(23.6)$ & $202(40.4)$ & $180(36.0)$ & \\
\hline & \multicolumn{6}{|c|}{$\mathrm{F}^{* *}=1.798, \mathrm{P}=0.128$} \\
\hline
\end{tabular}

* Chi- square test not applicable

**F- ANOVA test was used to compare between means of menopausal age of different educational Levels. $\chi^{2}=$ was used to compare between the proportion of menopause according to age in each of educational level

In this study although there was no significant variation in the mean age of menopause and years of formal education $(\mathrm{F}=1.798, \mathrm{P}=0.128)$, there was a significant association between menopause age group and years of formal education $\left(\chi^{2}=9.26, \mathrm{P}=0.009\right)$ with the highest percent of menopause age $>49$ years was among those with $\geq 13$ years of formal education and the lowest mean age of menopause and the highest percent $63.6 \%$ of early menopause was among those with 10-12 years of formal education as shown in Table 6 .

Table 7. Association of menopause age with pattern of menstrual cessation

\begin{tabular}{|c|c|c|c|c|c|c|}
\hline \multirow{2}{*}{$\begin{array}{l}\text { Pattern of } \\
\text { menstrual } \\
\text { cessation }\end{array}$} & \multirow{2}{*}{$\begin{array}{l}\text { Total } \\
\text { No }\end{array}$} & \multirow{2}{*}{$\begin{array}{l}\text { Mean } \pm \text { SD of } \\
\text { menopause age }\end{array}$} & \multicolumn{3}{|c|}{ menopause age group } & \multirow[b]{2}{*}{ CI } \\
\hline & & & $<45$ No(\%) & $45-49$ No(\%) & $>49 \mathrm{No}(\%)$ & \\
\hline Sudden (a) & 134 & $45.43 \pm 4.64$ & $54(40.3)$ & $52(38.8)$ & $28(20.9)$ & $44.63 / 46.22$ \\
\hline Gradual (b) & 266 & $48.17 \pm 3.99$ & $43(16.2)$ & $118(44.4)$ & $105(39.5)$ & $47.69 / 48.65$ \\
\hline $\begin{array}{l}\text { Recurrent (c) } \\
\text { bleeding }\end{array}$ & 100 & $48.17 \pm 4.08$ & $21(21.0)$ & $32(32.0)$ & $47(47.0)$ & $47.35 / 48.98$ \\
\hline \multirow[t]{2}{*}{$\begin{array}{l}\text { Total a\&(b,c) } \\
\mathrm{P}<0.001\end{array}$} & 500 & $47.44 \pm 4.35$ & $118(23.6)$ & $202(40.4)$ & $180(36.0)$ & \\
\hline & \multicolumn{6}{|c|}{$\mathrm{F}=20.950, \mathrm{P}<0.001 \chi^{2}=37.957, \mathrm{P}<0.001$} \\
\hline
\end{tabular}

*We not use Kruskall- Wallis test, we use ANOVA and $\chi^{2}$ for data analysis

Table 7 shows the variations in the mean age of menopause among women with different pattern of menstrual cessation were statistically significant $(\mathrm{F}=20,950, \mathrm{P}<0.001)$. The mean age was significantly lower among those with sudden cessation of menstruation than both gradual and recurrent bleeding $(\mathrm{P}<0.001)$. Age group at menopause was significantly associated with pattern of menstrual cessation $\left(\chi^{2}=37.957, \mathrm{P}<0.001\right)$ with the highest percent $40.3 \%$ of early menopause was detected in those with sudden cessation of menstruation with confidence interval regarding menopausal age group and pattern of menstrual cessation (44.63-46.22), (47.69-48.65), (47.35-48.98) respectively. 
Table 8. Association between knowledge of menopaused women and residence

\begin{tabular}{lcccccc}
\hline \multirow{2}{*}{ Residence } & \multicolumn{2}{c}{$\begin{array}{c}\text { Women had heard about } \\
\text { menopause No. (\%) }\end{array}$} & \multicolumn{2}{c}{$\begin{array}{c}\text { Knowledge about menopausal } \\
\text { symptoms No. (\%) }\end{array}$} & \multicolumn{2}{c}{$\begin{array}{c}\text { Awareness about HRT } \\
\text { No. (\%) }\end{array}$} \\
\cline { 2 - 7 } & Yes & No & Yes & No & Yes & No \\
\hline Rural & $41(97.6)$ & $16(38.1)$ & $1(2.4)$ & $26(61.9)$ & $1(2.4)$ & $41(97.6)$ \\
Urban & $426(93.0)$ & $32(7.0)$ & $267(58.3)$ & $191(41.7)$ & $67(14.6)$ & $391(85.4)$ \\
Total & $467(93.4)$ & $33(6.6)$ & $283(56.6)$ & $217(43.4)$ & $68(13.6)$ & $432(86.4)$ \\
& \multicolumn{2}{c}{$\mathrm{P}^{*}=0.345$} & \multicolumn{2}{c}{$\chi^{2}=6.39, \mathrm{P}=0.011$} & \multicolumn{2}{c}{$\mathrm{P}^{*}=0.031$} \\
\hline
\end{tabular}

*Fisher's exact test

Table 8 shows that knowledge about menopausal symptoms and awareness about hormone replacement therapy was significantly associated with residence $(\mathrm{p}=0.011, \mathrm{p}=0.031$ respectively) with higher proportion among urban women while no significant association was detected between hearing about menopause and residence $(\mathrm{P}=$ $0.345)$.

Table 9. Association between knowledge of menopaused women and occupation

\begin{tabular}{|c|c|c|c|c|c|c|}
\hline \multirow{2}{*}{ Residence } & \multicolumn{2}{|c|}{$\begin{array}{l}\text { Women had heard about } \\
\text { menopause No. (\%) }\end{array}$} & \multicolumn{2}{|c|}{$\begin{array}{c}\text { Knowledge about menopausal } \\
\text { symptoms No. (\%) }\end{array}$} & \multicolumn{2}{|c|}{$\begin{array}{c}\text { Awareness about HRT } \\
\text { No. (\%) }\end{array}$} \\
\hline & Yes & No & Yes & No & Yes & No \\
\hline Housewife & $395(94.0)$ & $25(5.9)$ & $217(51.7)$ & $203(48.3)$ & $36(8.6)$ & $384(91.4)$ \\
\hline Unskilled* & $29(82.8)$ & $6(17.1)$ & $24(68.6)$ & $11(31.4)$ & $8(22.9)$ & $27(77.1)$ \\
\hline $\begin{array}{l}\text { Skilled**\& } \\
\text { Professional }\end{array}$ & $43(95.5)$ & $2(4.4)$ & $42(93.3)$ & $3(6.7)$ & $24(53.3)$ & 21(46.7) \\
\hline Total & $\begin{array}{r}467(93.4) \\
\chi^{2}=6.9\end{array}$ & $\begin{aligned} & 33(6.6) \\
= & 0.031\end{aligned}$ & $\begin{array}{r}283(56.6) \\
\chi^{2}=30\end{array}$ & $\begin{array}{l}217(43.4) \\
<0.001\end{array}$ & $\begin{array}{r}68(13.6) \\
\chi^{2}=72 .\end{array}$ & $\begin{array}{l}432(86.4) \\
\mathrm{P}<0.001\end{array}$ \\
\hline
\end{tabular}

*Manual partly Skilled or unskilled occupation

** Non-manual skilled or semi skilled occupation categorized with professional occupation for sake of statistical analysis

There was significant association between hearing about menopause $(\mathrm{P}=0.031)$, menopausal symptoms ( $\mathrm{P}$ $<0.001)$ and HRT $(\mathrm{P}<0.001)$ with occupation with higher proportion among skilled and professional occupations as shown in Table 9.

\section{Discussion}

The mean age at menopause in this study was $47.44 \pm 4.35$ years with median age of 48 . This result is more or less near to those reported in Baghdad (Dhia Al-Deen and Sadik, 2009), Northern Iran (Delavar and Hajiahmadi, 2011), Malay (Jahanfar et al, 2006) and Pakistan (Baig and Karim, 2006). The mean age at menopause in Asia is probably lower than in developed countries (Gold et al, 2001) and mean age of menopause in this study is lower than the mean age of menopause in similar studies in Poland (Kaczmarek, 2007) that reported the median age at natural menopause 51.2 years, USA (Gold et al, 2001) and Italian (Meschia et al, 2000) mean age at natural menopause were 51.4 years, 50.9 years respectively. Compared to the result of other studies in Asian and African countries (Jahanfar et al, 2006; Loutfy et al, 2006; Al-Sejari, 2005; Bairy et al, 2009) the result of this study is lower by one year. Possible explanation for this wide difference in menopausal ages may be related to the fact that ethnic, biological and cultural background may have an impact on age at menopause (Castelo-Branco, 2005; Ginsburg, 1991) or methodological differences between the present study and similar studies such as using retrospective recall during data collection.

In this study $93.4 \%$ of menopaused women heard about menopause and $56.6 \%$ had previous knowledge about symptoms this result is higher than the result of study conducted in Hyderabad Pakistan revealed that $78.79 \%$ of women heard about menopause but only $15.87 \%$ had knowledge about symptoms (Nusrat et al, 2008).

In the present study $71.2 \%$ of menopaused women stated that their lives altered after cessation of menstruation and perceiving menopause in a negative way in $53 \%$ which was similar to the result of a study conducted in Karachi Pakistan (Malik,2008) while 75\% among Nigerian women (Ozumba et al,2004) perceive menopause in 
a negative way. In another study, Thai women perceived menstruation to be an indicator of living and health (Punyahotra and Dennerstein, 1997) while respond to menopause in a negative way which may be attributed to the end of fertility, youth and creativity (Castelo-Branco, 2005).

In this study $85.8 \%$ of women perceived menopause as a natural condition which goes parallel with the perception of women in eastern societies who considered menopause as a natural process (Loutfy et al, 2006; Bairy et al, 2009; Blalt, 1953; Chang 1995; Adler, 2000).

Awareness and the use of hormone replacement therapy are generally low among populations from different Asian countries (Huang, 2010) in agreement with result of this study which revealed that $13.6 \%$ of women were aware about HRT.

More than two thirds of menopaused women $71.8 \%$ in a Danish study had discussed the menopause with a doctor; the more problematic the symptoms, the greater the likelihood that the women did consultation (Hvas et al, 2003) while in this study $49 \%$ of the women had consulted a physician and $46.6 \%$ discuss menopausal symptoms with the doctors, this may attributed to that women may not seek medical advice because they believe that menopause, like puberty, includes natural human changes that are part of development and ageing process (Wood \& Mitchell, 1999).

In this study $82.4 \%$ of menopaused women were not smoker and we couldn't find significant association between age at menopause and smoking habit, while a study in Egypt (Loutfy et al, 2006) reported higher percentage of non smoker; $98.4 \%$ and this attributed to the cultural differences $.34 .6 \%$ of menopaused women in this study mentioned that sexual desire decreased which could be attributed to that sexual life is a taboo topic that it is considered very private and may have effect on their answer whether affect or not and this result is not so differ with results of studies in Turkish population (Ayranci et al, 2010) and Karachi Pakistan (Ozumba et al, 2004) which reported $39.7 \%, 32.3 \%$ decrease sexual desire respectively.

In this study $84.8 \%$ of menopaused women told their husband about their cessation of menstruation and this may attributed to their perception about the menopause as a natural condition.

Results show that $51.8 \%, 16.0 \%$ of menopaused women complaining from vaginal dryness and dyspareunia respectively while a study among Saudi women reported lower percentage, $8.5 \%$ complaining from vaginal dryness and none of them experiencing dyspareunia (Al-Sejari, 2005) and 23.6\% complaining from dysuria. While higher percentage of dysuria 35.1\% reported in a study from Egypt (Loutfy et al, 2006).

Regarding psychological symptoms among the menopaused women in this study $58.6 \%$ with loss of short term memory which is inconsistent with the result of study done in Hyderabad Pakistan (Nusrat et al, 2008) revealed $62.10 \%$ with loss of short term memory and $9.4 \%$ of menopaused women in this study had depressed mood which is lower than that reported from study in Egypt which revealed that $60.7 \%$ were complained from this symptoms (Loutfy et al, 2006) probably this wide variation related to methodological differences and under estimation of depression in our community due to stigma and shame from mental disorders..

There was statistically significant association between age groups at menopause and education; highest percent of menopause age $>49$ years was detected among those with $\geq 13$ years of formal education and a study in Baghdad (Dhia \& Sadik, 2009) also reveals significant association and this attributed to that educated women more likely better to deal with changes in menstrual period, consult doctors and receiving medications.

This study shows that sudden cessation of menstruation was significantly associated with earlier menopause than gradual cessation of menstruation and recurrent bleeding. This may attributed to that abrupt cessation may accompany sudden psychological trauma (pituitary shock) or may reflect abnormal or pathological ovarian failure that may occur at an earlier age (Vermeulen, 1993) and this finding coincides with the result of other studies in Baghdad (Dhia \& Sadik, 2009) and Egypt (Hidayet et al, 1999).

Knowledge about menopausal symptoms and awareness of hormonal replacement therapy; the results show that there was significant association with residence, the highest percent of menopaused women from urban area had previous knowledge about menopausal symptoms and aware about HRT and this due to availability of different primary health care centers and consultation clinic with easier access to these health centers among urban peoples. Concerning occupation, highest percent of menopaused women with previous knowledge about menopausal symptoms and awareness about HRT were among skilled and professional occupation and this is in agreement with the result of a study in Egypt (Loutfy et al, 2006) and this attributed to that those who have skilled and professional occupation have better educational level and when they are complaining from any symptoms they consult a physician and getting more information. 


\section{Conclusion}

Most of menopaused women perceive menopause as natural condition and not aware about hormone replacement therapy and the mean age of menopause is comparable to that mean reported in other part of Iraq. Among menopaused women tiredness was the most common complaint was followed by hot flushes and night sweats.

\section{References}

Adler, S. R., Fosket, J. R., kagawa-singer, M., Mc Graw, S. A., Wongkin-Evaon, Gold, E., et al. (2000). Conceptualizing menopause and midlife: Chinese American and Chinese women in the US. Maturitas, 35, 11-23. http://dx.doi.org/10.1016/S0378-5122(00)00090-6

Al-Sejari, M. M. (2005). Age at natural menopause and menopausal symptoms among Saudi Arabian women in Al-Khobar. ETD center. Retrieved from http://etd.ohiolink.edu/view. cgi? osu1116611916

Avis, N. E. (1996). Women's perceptions of the menopause. Eur Menopause J, 3, 80-3.

Avis, N. E., \& McKinley, S. M. (1991). A longitudinal analysis of women's attitudes toward the menopause: results from the Massachusetts Women's Health Study. Maturitas, 13(1), 65-79. http://dx.doi.org/10.1016/ 0378-5122(91)90286-Y

Ayatollahi, S. M. T., Ghaem, H., Ayatollahi, S. A. R. (2005). Sociodemographic factors and age at natural menopause in Shiraz, Islamic Republic of Iran. East Mediterr Health J, 11(2), 146-54.

Ayers, B., Forshow, M., \& Hunter, M. S. (2010). The impact of attitudes toward the menopause on women's symptom experience: A systemic review. Maturitas, 65(1), 28-36. http://dx.doi.org/10.1016/j.maturitas.20 09.10 .016

Ayranci, U., Orsal, O., Arslan, G., \& Emeksiz, D. F. (2010). Menopause status and attitudes in a Turkish midlife female: an epidemiological study. BMC Women's Health, 10(1). http://dx.doi.org/10.1186/1472-6874-10-1

Baig, L. A., \& Karim, S. A. (2006). Age at menopause, and knowledge of and attitudes to menopause, of women in Karachi, Pakistan. Menopause Int, 12(2), 71-4.

Bairy, L., Adiga, S., Bhat, P., \& Bhat, R. (2009). Prevalence of menopausal symptoms and quality of life after menopause in women from south India. Aust $N$ Z J Obestet Gynecol, 49(1), 106-9. http://dx.doi.org/10.1111/j.1479-828X.2009.00955.x

Blalt, M. H. G., Wiesbader, H., \& Kupperman, H. S. (1953). Vitamin E and climacteric syndrome: failure of effective control as measured by menopausal index. Arch Intern Med, 91, 792-9. http://dx.doi.org/10.1001/ archinte.1953.00240180101012

Block, E. (1952). Quantitative morphological investigations of the follicular system in women. Acta Anat (Basel), 14, 108-23. Abstract. http://dx.doi.org/10.1159/000140595

Castelo-Branco, C., Palacios, S., Mostajo, D., Tobar, C., \& von Helde, S. (2005). Menopausal transition in Movima women, a Bolivian native American. Maturitas, 16(51), 380-5. http://dx.doi.org/10.1016/j.maturit as.2004.09.004

Chang, C., Chow, S. N., \& Hu, Y. (1995). Age of menopause of Chinese women in Taiwan. Int J Gynaecol Obstet, 49, 191-2. http://dx.doi.org/10.1016/0020-7292(95)02354-F

Delavar, M. A., \& Hajiahmadi, M. (2011). Factors affecting the age in normal menopause and frequency of menopausal symptoms in Babol, Northern Iran. Iranian Red Crescent Medical Journal, 13(3), 1-7.

Dhia Al-Deen, L., \& Sadik, F. (2009). Age at natural menopause and factors influencing its timing in a sample of Iraqi women in Baghdad. Iraqi J. Comm. Med, 1, 1-7.

Edmonds, K., Gebbie, E. A., Hay, P., Ingomells, S., Monga, A., Norman, J., et al. (1991). Menopause. In: Monga A, editor. Gynecology by ten teachers. $18^{\text {th }}$ ed. London: Hodder Arnold; 2006. P. 207-17.

Ginsburg, J. (1991). What determines the age at menopause? $\mathrm{Br}$ Med J, 302, 1288-99. http://dx.doi.org/10.1136/bmj.302.6788.1288

Gold, E. B., Bromberger, J., Crawford, S., Samuels, S., Greendale, G. A., Harlow, S. D., et al. (2001). Factors associated with age at natural menopause in a multiethnic sample of middle women. Am J Epidemiol, 153(9), 865-74. http://dx.doi.org/10.1093/aje/153.9.865

Hassa, H., Tanir, H. M., Yildrim, A., Senses, T., Oge, T., \& Mutlu, F. S. (2005). Associated factors with urogenital score in natural and surgical menopause. Maturitas, 16(52), 65-9. http://dx.doi.org/10.1016/j.maturitas.2004.12.005 
Hidayet, N. M., Sharaf, S. A., Aref, S. R., Tawfik, T. A., \& Moubarak II. (1999). Correlates of age at natural menopause: a community-based study in Alexandria. East Mediterr Health J, 5(2), 307-19.

Huang, K. E. (2010). Menopause perspectives and treatment of Asian women. Semin Reprod Med, 28(5), 396-403. Abstract. http://dx.doi.org/10.1055/s-0030-1262899

Hvas, L., Thorsen, H., \& Sondergaard, K. (2003). Discussing menopause in general practice. Maturitas, 46(2), 139-46. http://dx.doi.org/10.1016/S0378-5122(03)00164-6

Jahanfar, S. H., Abdul Rahim, B. A., Shah Reza, B. K., Nor Azura, B. T., Sharifa Nora, B. T., Siti Asma, B. T. (2006). Age of menopause and menopausal symptoms among Malaysian women who referred to health clinic in Malaysia. Shiraz E-Medical J, 7(3), 1-9.

Kaczmarek, M. (2007). The timing of natural menopause in Poland and associated factors. Maturitus, 57(2), 139-53. http://dx.doi.org/10.1016/j.maturitas.2006.12.001

Kowalcek, I., Rotte, D., Banz, C., \& Diedrich, K. (2005). Women's attitude and perceptions towards menopause in different cultures. Cross-cultural and intra-cultural comparison of pre-menopausal and post-menopausal women in Germany and in Papua New Guinea. Maturitas, 51(3), 227-35. http://dx.doi.org/10.1016/j.maturi tas.2004.07.011

Leon, P., Chedraui, P., Hidalgo, L., \& Ortiz, F. (2007). Perceptions and attitudes toward the menopause among middle aged women from Guayaquil, Ecuador. Maturitas, 57(3), 233-8. Abstract. http://dx.doi.org/10.1016/j.maturitas.2007.01.003

Lobo, R. A. (2007). Menopause: Endocrinology, consequences of estrogen deficiency, effects of hormone replacement therapy, treatment regimens. In: Katz VL, Lentz GM, Lobo RA, Gershenson DM, editors. Comprehensive gynecology. $5^{\text {th }}$ ed. Philadelphia: Mosby Elsevier. P. 1039-65. http://dx.doi.org/10.1016/B978-0-323-02951-3.50045-5

Loutfy, I., Abdel Aziz, F., Dabbous, N. I., \& Hassan, M. H. A. (2006). Women's perception and experience of menopause: a community-based study in Alexandria, Egypt. East Mediterr Health J, 12(Suppl 2), S93-106.

Malik, H. S. (2008). Knowledge and attitude towards menopause and hormone replacement therapy (HRT) among postmenopausal women. J Pak Med Assoc, 58(4), 164-7.

Meschia, M., Pancini, F., Modena, A. B., De Alovsio, D., Gambacciani, M., Parazzini, F., et al. (2000). Determinants of age at menopause in Italy: results from a large cross- sectional study. Maturitus, 34(2), 119-25. http://dx.doi.org/10.1016/S0378-5122(99)00095-X

Nusrat, N., Nishat, Z., Gulfareen, H., Aftab, M., \& Asia, N. (2008). Knowledge, attitude and experience of menopause. J Ayub Med Coll Abbottabad, 20(1), 56-9.

Ozumba, B. C., Obi, S. N., \& Obikili, Waboso, P. (2004). Age, symptoms and perception of menopause Among Nigerion women. J Obestet Gynecol Ind, 54(6), 575-8.

Panay, N. (2007). Menopause and the postmenopausal women. In: Edmonds DK, editor. Dewhurts' textbook of obstetrics and gynecology. $7^{\text {th }}$ ed. London: Black Well. P. 479-94. http://dx.doi.org/10.1002/9780470753354.ch47

Punyahotra, S., \& Dennerstein, L. (1997). Menopausal experience of Thai women, Part 2: The cultural context. Maturitas, 26(1), 9-14. http://dx.doi.org/10.1016/S0378-5122(96)01078-X

Sallam, H., Galal, A. F., \& Rashed, A. (2006). Menopause in Egypt: past and present perspectives. Climacteric, 9(6), 421-9. http://dx.doi.org/10.1080/13697130601030170

Theisen, S. C., Mansfield, P. K., Seery, B. L., \& Voda, A. (1995). Predictors of midlife women's attitudes towards menopause. Health Values, 19(3), 22-31.

Vermeulen, A. (1993), Environmental, human reproduction, menopause and andropause. Environ health perspect, 101, 91-100.

WHO. (1996). Research on menopause in the 1990s: report of a WHO scientific group. Geneva: WHO; (Technical Report Series). P. 866.

Wong, S. J., Lue, S. R., Juang, K. D., \& Chiu, L. M. (2001). The Kinmen women-health investigation: a menopauseal study of a population aged 40-54. Maturitas, 39(2), 117-20. http://dx.doi.org/10.1016/S03785122(01)00193-1

Woods, N. F., \& Mitchell, E. S. (1999). Anticipating menopause: observations from the Seattle Midlife Women's Health Study. Menopause, 6, 167-73. 